\title{
clicSANDMac for OSeMOSYS: a user-friendly interface for macOS users using open-source optimisation software for energy system planning
}

\section{Carla Cannone ( $D$ C.Cannone@lboro.ac.uk)}

STEER Centre, Geography \& Environment, Loughborough University, United Kingdom; Imperial College London, United Kingdom https://orcid.org/0000-0002-1214-8913

\section{Nicki de Wet}

\section{Abhishek Shivakumar}

STEER Centre, Geography \& Environment, Loughborough University, United Kingdom; Imperial College London, United Kingdom; United Nations Department of Economic and Social Affairs (UNDESA), United States https://orcid.org/0000-0002-2535-4134

\section{Alex Kell}

Imperial College London, United Kingdom https://orcid.org/0000-0003-3100-4306

\section{Naomi Tan}

STEER Centre, Geography \& Environment, Loughborough University, United Kingdom; Imperial College London, United Kingdom https://orcid.org/0000-0001-7957-8451

\section{Rudolf Yeganyan}

STEER Centre, Geography \& Environment, Loughborough University, United Kingdom; Imperial College London, United Kingdom https://orcid.org/0000-0001-9325-8147

\section{Long Seng To}

STEER Centre, Geography \& Environment, Loughborough University, United Kingdom https://orcid.org/0000-0003-4676-5810

\section{John Harrison}

STEER Centre, Geography \& Environment, Loughborough University, United Kingdom https://orcid.org/0000-0002-6434-5142

\section{Mark Howells}

STEER Centre, Geography \& Environment, Loughborough University, United Kingdom; Imperial College London, United Kingdom https://orcid.org/0000-0001-6419-4957

\section{Research Article}

Keywords: Open source, User Interface (UI), OSeMOSYS, Energy system modelling, Linear Programming, clicSAND 
DOI: https://doi.org/10.21203/rs.3.rs-1384770/v1

License: (c) (1) This work is licensed under a Creative Commons Attribution 4.0 International License. Read Full License 


\section{Abstract}

clicSAND is a user interface for OSeMOSYS users to analyse energy system models in terms of investment planning and optimal allocation of resources. The first version was only available for Windows users with at least 8 GB RAM and an installed Windows Access database to visualise the results. This paper presents an updated version of the software called clicSANDMac, which was specifically developed for macOS OSeMOSYS users and overcomes the previous limitations - as described in Section 1. The main changes to the software, its functionalities, and configuration are presented in Section 2. The paper ends with Section 3, which provides suggestions for future work and the potential impact of the clicSANDMac software.

\section{Metadata}

\begin{tabular}{|c|c|c|}
\hline $\mathrm{Nr}$ & $\begin{array}{ll}\text { Code } & \text { metadata } \\
\text { description } & \end{array}$ & Please fill in this column \\
\hline $\mathrm{C} 1$ & Current code version & V.2.0. \\
\hline $\mathrm{C} 2$ & $\begin{array}{l}\text { Permanent link to } \\
\text { code/repository used for } \\
\text { this code version }\end{array}$ & https://github.com/ClimateCompatibleGrowth/clicSANDMac \\
\hline$\overline{\mathrm{C} 3}$ & $\begin{array}{lc}\text { Permanent link } & \text { to } \\
\text { reproducible capsule } & \end{array}$ & Not Available \\
\hline $\mathrm{C} 4$ & Legal code license & CC0 1.0. \\
\hline $\mathrm{C} 5$ & $\begin{array}{lll}\text { Code } & \text { versioning } & \text { system } \\
\text { used } & & \end{array}$ & None \\
\hline $\mathrm{C} 6$ & $\begin{array}{lr}\text { Software } & \text { code } \\
\text { languages, tools } & \text { and } \\
\text { services used }\end{array}$ & C\# \\
\hline $\mathrm{C} 7$ & $\begin{array}{lr}\text { Compilation } & \\
\text { requirements, } & \text { operating } \\
\text { environments } & \text { and } \\
\text { dependencies } & \end{array}$ & .NET Runtime \\
\hline $\mathrm{C} 8$ & $\begin{array}{l}\text { If available, link to } \\
\text { developer } \\
\text { documentation/manual }\end{array}$ & $\begin{array}{l}\text { https://www.open.edu/openlearncreate/course/view.php? } \\
\text { id=8409 }\end{array}$ \\
\hline $\mathrm{C} 9$ & $\begin{array}{lll}\begin{array}{l}\text { Support } \\
\text { questions }\end{array} & \text { email } & \text { for } \\
\end{array}$ & C.Cannone@lboro.ac.uk \\
\hline
\end{tabular}

\section{Description Of The Software-update Motivation and significance}

\section{Scientific background and motivation for developing the software}

The development of the first version of the clicSAND software for the users of the Open-Source energy Modelling System (OSeMOSYS) focused on user-friendliness. clicSAND is open-source software used for the analysis of energy system models to mobilise investments in energy planning. As described in [1], no 
programming skills are required to get started and use this software, as the user only interacts with a user interface (UI) and Microsoft Excel files for data management. However, in the first version, the clicSAND software was only available to Windows users, and 8 GB RAM and Windows Access were required to run the models smoothly. To overcome these limitations, a second version of the software was developed. clicSANDMac offers improved features compared to its first version, as described in the following section. It was developed specifically for macOS users and is available for download on Github [2], with the aim of expanding the audience that can benefit from this public good. It is important to note that this is the first open-source software for OSeMOSYS users available on macOS. In addition, a new opensource and freely available online course tailored for macOS users is now available on the Open Learn Create website [3]. The structure of the course, as well as the quizzes and learning outcomes, is the same as in the Windows version.

\section{Software description}

\section{Software Architecture}

clicSANDMac is written in C\# and is available under an MIT license, which only minimally restricts reuse and therefore has a high degree of license compatibility [4]. The first version of the software was originally licensed under a Creative Commons CC0-1.0 waiver [5].

\section{Software Configuration}

The first update concerns the user interface ( $\mathrm{UI})$. As can be seen in Figure 1, the "Open Log" button has been removed and only the "Run" and "Export Templates" buttons have been retained. The "Run" button executes the two open-source solvers and an additional Python code that was not included in the first version of the software. The user does not need to interact directly with this Python code as it is embedded in the $\mathrm{Ul}$ of the software. The Python code was included to overcome the biggest challenge in creating the macOS version of clicSAND - visualising the results using Microsoft Access database. On the other hand, the "Export Templates" button does not save a copy of the Access database template, only the following files:
(a) Blank SAND Excel interface [.xlsm] (as before);
(b) OSeMOSYS code [.txt] (as before);
(c) New result template [.xlsx].

Another crucial difference is that the data source to be selected in clicSANDMac is in .txt format and not in the .xlsm format of its Windows counterpart. The data source in .txt format is created by copying and 
pasting the entire "ToDataFile" tab in the Excel interface SAND into a new .txt file. On a macOS machine, this would be a default app called "TextEdit".

\section{Software Functionalities}

As mentioned earlier, the Access database is not compatible with macOS and no alternative open-source databases have been found that perform the required functions. The Python code added to the "Run" button post-processes the results generated by the solvers and converts them to a CSV file, which already has the format required by the newly developed results visualisation template (Figure 2). The Python code thus bypasses the need for an Access database and could also be implemented in the Windows version of clicSAND in the future.

\section{Results Visualisation Template}

The data within the CSV result file generated by the clicSANDMac software must be manually copied by the user into the "ResultsData" tab of the new results visualisation template (Figure 3 ). The user must also make sure that previous data remaining in the new results visualisation template is removed before copying and pasting the results. The results are then updated automatically via the "Refresh" button within the "PivotTable Analyze" ribbon for the individual tabs of the chart (i.e. AnnualElecProduction, ElecProductionByTS etc.) without having to import the data from the Access database (Figure 4).

\section{Conclusion and extension}

\section{Impact and use of clicSANDMac}

clicSANDMac is being used to teach master's students on the Climate Change Politics and Policy master's course at Loughborough University [6] and master's students in Environmental Technology at Imperial College London [7]. It will also be used during the international capacity building event called the Joint Summer School of Modelling Tools for Sustainable Development at the International Centre for Theoretical Physics (ICTP) in June 2022 [8]. This event will train energy analysts from the Global South to acquire energy modelling skills and mobilise the investments needed for the sustainable development of their countries.

The new clicSANDMac functionality for visualising results will also be used in the Windows version of the software to align the process for all OSeMOSYS users. Future developments will also add a new button to the user interface to make the input data compatible with OSeMOSYS cloud functions for visualisation in a reference energy system (RES). This latter development will help to identify errors in the models.

\section{Declarations}

Declaration of competing interest 
The authors declare that they have no known competing financial interests or personal relationships that could have influenced the work reported in this paper.

CRediT Author Statement

Carla Cannone: Conceptualisation; Data curation; Investigation; Methodology; Software; Formal analysis; Validation; Visualisation; Writing - Original Draft. Nicki de Wet: Software; Visualisation;

Validation. Abhishek Shivakumar: Software; Visualisation; Validation; Review. Alex Kell: Software; Visualisation; Validation; Review. Naomi Tan: Software; Validation; Visualisation; Review; Rudolf Yeganyan: Validation; Review. Long Seng To: Review. John Harrison: Review. Mark Howells: Conceptualisation, Review.

Acknowledgements

This paper has been written with the support of the Climate Compatible Growth (\#CCG) Programme of the UK's Foreign, Development and Commonwealth Office (FCDO). The views expressed in this paper do not necessarily reflect the UK government's official policies

\section{References}

1. C. Cannone et al., "clicSAND for OSeMOSYS: a user-friendly interface using open-source optimisation software for energy system modelling analysis | Research Square," 2022, Accessed: Feb. 16, 2022. [Online]. Available: https://www.researchsquare.com/article/rs-1338761/v1.

2. "ClimateCompatibleGrowth/clicSANDMac." https://github.com/ClimateCompatibleGrowth/clicSANDMac (accessed Feb. 22, 2022).

3. "OLCreate: PUB_5398_1.0 (MacOS Users) Energy and Flexibility Modelling: OSeMOSYS \& FlexTool." https://www.open.edu/openlearncreate/course/view.php?id=8409 (accessed Feb. 16, 2022).

4. J. H. Saltzer and D. Walden, "The origin of the 'MIT license,"' IEEE Ann. Hist. Comput., vol. 42, no. 4, pp. 94-98, Nov. 2020, doi: 10.1109/MAHC.2020.3020234.

5. "Creative Commons - CCO 1.0 Universal." https://creativecommons.org/publicdomain/zero/1.0/ (accessed Feb. 22, 2022).

6. "Climate Change Politics and Policy Degree | Postgraduate study | Loughborough University." https://www.lboro.ac.uk/study/postgraduate/masters-degrees/a-z/climate-change-politics-andpolicy/\#modules_semester_2 (accessed Feb. 02, 2022).

7. "MSc Environmental Technology | Study | Imperial College London." https://www.imperial.ac.uk/study/pg/environmental-policy/environmental-technology/ (accessed Feb. 23, 2022).

8. "Joint Summer School on Modelling Tools for Sustainable Development 2022 | (smr 3763) (06-17 June 2022)." http://indico.ictp.it/event/9879/overview (accessed Feb. 24, 2022). 


\section{Figures}

\section{Figure 1}

clicSANDMac software landing page of the User Interface (UI)

\section{Figure 2}

clicSANDMac software configuration

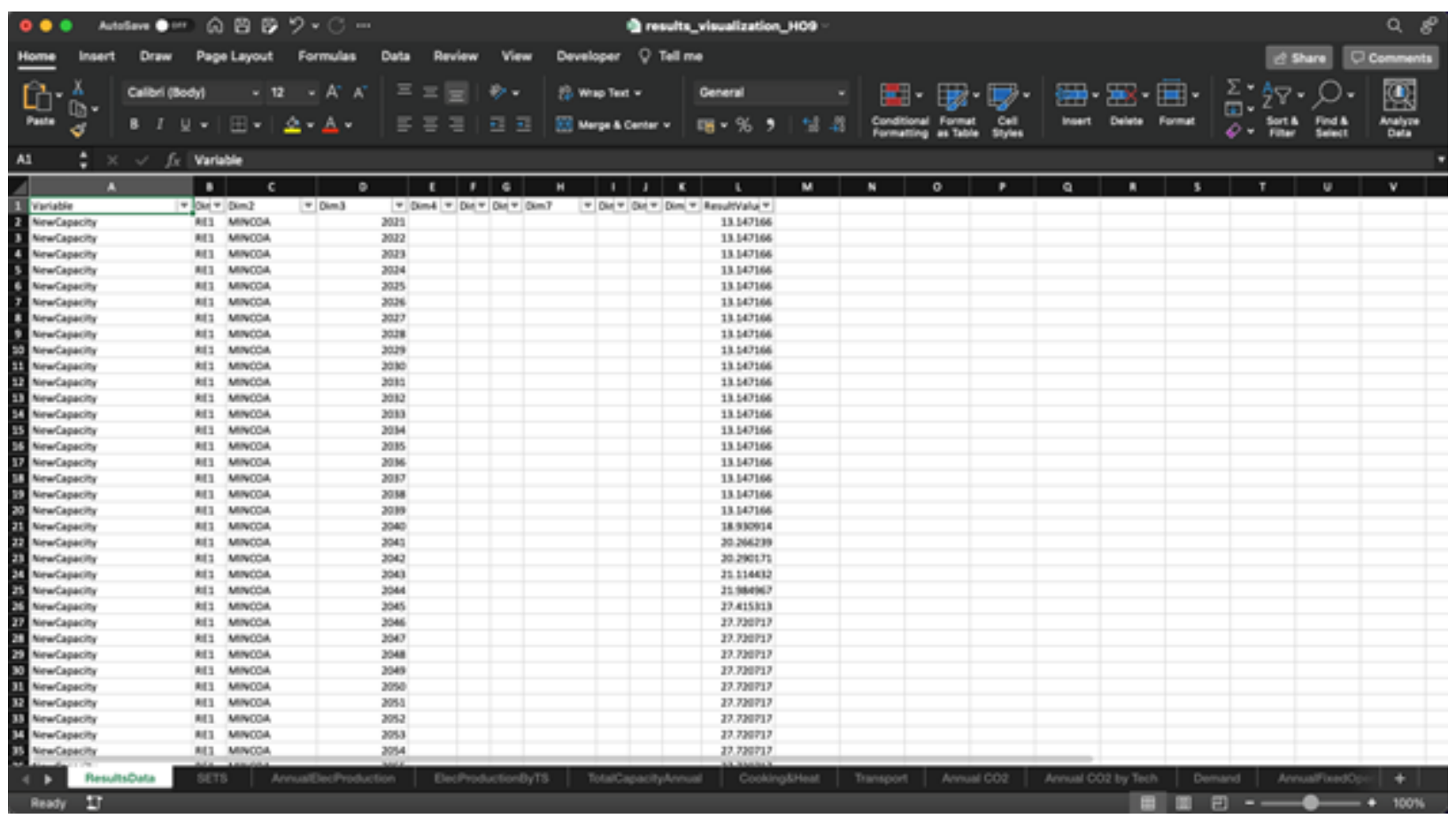

\section{Figure 3}

New Results Visualization Template in Excel

\section{Figure 4}

Output from the New Results Visualisation Template in Excel. This can be updated by clicking on the "Refresh" button in the "PivotTable Analyze" ribbon. 